\title{
Health Policy and Planning
}

\section{Weighing the options for delivery care in rural Malawi: community perceptions of a policy promoting exclusive skilled birth attendance and banning traditional birth attendants.}

\begin{tabular}{|r|l|}
\hline Journal: & Health Policy and Planning \\
\hline Manuscript ID & HEAPOL-2018-Aug-0429.R1 \\
\hline Manuscript Type: & Original Manuscript \\
\hline Country of Expertise: & United Kingdom, Malawi \\
\hline Keywords: & $\begin{array}{l}\text { maternal health, maternal mortality, policy implementation, policy } \\
\text { analysis, rural health, women-s health }\end{array}$ \\
\hline & \\
\hline
\end{tabular}

\section{SCHOLARONE ${ }^{\text {M }}$ Manuscripts}

This is a pre-copyedited, author-produced PDF of an article accepted for publication in Health Policy and Planning following peer review. The version of record Uny I, de Kok B \& Fustukian S (2019) Weighing the options for delivery care in rural Malawi: community perceptions of a policy promoting exclusive skilled birth attendance and banning traditional birth attendants. Health Policy and Planning, 34 (3), pp. 161-169 is available online at: https://doi.org/10.1093/heapol/czz020 


\begin{abstract}
To address its persistently high maternal mortality, the Malawi government has prioritised strategies promoting skilled birth attendance and institutional delivery. However, in a country where $80 \%$ of the population resides in rural areas, the barriers to institutional deliveries are considerable. As a response, Malawi issued Community Guidelines in 2007 that both promoted skilled birth attendance and banned the utilization of traditional birth attendants for routine deliveries. This grounded theory study used interviews and focus groups to explore community actors' perceptions regarding the implementation of this policy and the related affects that arose from its implementation. The results revealed the complexity of decisionmaking and delivery care-seeking behaviours in rural areas of Malawi in the context of this policy. Although women and other actors seemed to agree that institutional deliveries were safer when complications occurred, this did not necessarily ensure their compliance. Furthermore, implementation of the 2007 Community Policy aggravated some of the barriers women already faced. This innovative bottom-up analysis of policy implementation showed that the policy had further ruptured linkages between community and health facilities, which was ultimately detrimental to the continuum of care. This study helps fill an important gap in research concerning maternal health policy implementation in LICs, by focusing on the perceptions of those at the receiving end of policy change. It highlights the need for globally promoted policies and strategies to take better account of local realities.
\end{abstract}

\title{
Introduction
}


1 The globally recommended strategy to reduce the high ratios of maternal mortality in low 2 income countries (WHO. et al. 2015) is to promote policies supporting 'skilled birth 3 attendance', the conjunction of a skilled birth attendant (SBA) and an enabling environment 4 which includes facilities that can provide emergency obstetric care, including necessary 5 drugs and transport for referrals (Hussein, Clapham 2005). As a result, ratios of skilled birth 6 attendance have become one of the main indicators for progress towards maternal mortality 7 reduction (as evidenced in the UN Millennium Development Goals (MDG) targets and 8 subsequent Sustainable Development Goals (SDGs). However, since the 2000s, the focus 9 on skilled birth attendance has been at the exclusion of other strategies that have been 10 deemed ineffective to reduce maternal mortality. One of the strategies abandoned has been 11 the training and utilization of traditional birth attendants (TBAs) for routine deliveries (Miller et al. 2003). TBAs are lay midwives who learned to conduct deliveries and to assist women "through apprenticeship to other traditional birth attendants" (WHO 1979). Skilled birth attendants (SBAs), by contrast, are defined as "people with midwifery skills (for example, doctors, midwives, nurses) who have been trained to proficiency in the skills necessary to manage normal deliveries and diagnose or refer obstetric complications" (WHO 1999). SBAs are " competent maternal and newborn health $(\mathrm{MNH})$ professionals educated, trained and regulated to national and international standards"(WHO et al. 2018, p.2) whose presence at birth is considered key to ending preventable maternal mortality.

The global policy focus on skilled birth attendance also reflects the dominance of biomedical knowledge in childbirth as 'authoritative knowledge'. Authoritative knowledge is a-concept defined by Jordan, and refers to the knowledge on the basis of which decisions are made in childbirth-defined as follows: consensus, come to carry more weight than others, either because they explain the 

(Jordan 1997, p.56)

Biomedical knowledge has become the dominant authoritative knowledge in childbirth.

Coupled with a widespread discourse of risk that stresses the dangers of pregnancy and deliveries (Smith, V. et al. 2012), it has reinforced the notion that women are only safe where technology and diagnostic tests can be deployed by skilled birth attendants._TBAs, on the other - dohand, do not fit the 'skilled' description since they are not medically trained-_and belong to another knowledge system of childbirth, which is why they have been excluded from global safe motherhood strategies. This was despite most TBAs having been trained in many countries for decades on the basics of safe and clean delivery, the danger signs of childbirths and steps to take to refer complications to hospital (Wendland 2015). A number of systematic reviews have indicated that TBA training was ineffective both in reducing maternal mortality (Sibley et al. 2004, Sibley et al. 2012) and in addressing delivery complications (Smith, J. B. et al. 2000, Bailey et al. 2002). As a result, the WHO issued a clear statement dissuading countries from TBA utilisation (WHO 1999). Government in 2007 and called The Guidelines for Community Initiatives for Reproductive Health [henceforth referred to as "the 2007 Community Policy"]. This policy was designed to support maternal mortality reduction through promoting community engagement (Republic of Malawi Ministry of Health 2007a). At the time the policy was issued, Malawi was seen as significantly off-track in meeting MDG5 (Bhutta et al. 2010), with an estimated maternal 
55 mortality ratio of 800 per 100,000 live births (Colbourn et al. 2013). Following a rapid assessment of TBAs' roles that declared their skills insufficient to support deliveries particularly when complications occur- (Republic of Malawi Ministry of Health 2006), the 2007 Community Policy was issued to promote skilled birth attendance and to advise district health staff on how to mobilise community members for maternal mortality reduction. The policy clearly stated that TBAs would now be "conducting deliveries only in unavoidable circumstances" (Republic of Malawi Ministry of Health 2007a). Such circumstances were not defined, and the policy has been referred to as the 'TBA ban' by the general public. The policy also gave village headpersons $(\mathrm{VH})$ and traditional chiefs a significant role in supporting its implementation and enforcement, including the use of bylaws, which many have used to penalize women who failed to comply with the policy recommendations (Banda 2013, Godlonton, Okeke 2016), as well as TBAS who may assist them without cause.

$\underline{\text { In alignment with the global evidence and recommendations (WHO 1999, De Brouwere, Van }}$ Lerberghe 2001), The policymakers' expectation was that, with the 2007 Community Policy, TBA-assisted deliveries would eventually disappear and skilled birth attendance would rise (Godlonton, Okeke 2016), ensuring a decrease in maternal mortality. This expectation seems to have been partly fulfilled: whilst in 2007 , the estimated number of deliveries by skilled birth attendants was $71.4 \%$ and deliveries by TBAs were $14.4 \%$ (Colbourn et al. 2013); in 2016 the Government reported that SBAs_assisted 87\% of deliveries, whereas TBAs were only assisted $3 \%$, friends and relatives $4 \%$, and $2 \%$ remained unassisted (NSO Malawi, ICF 2017). However, this increase in skilled birth attendance has been less pronounced in some areas, such as in the district of Lilongwe, where TBA-assisted births are $6.1 \%$ and in more isolated rural areas such as Nkhotakhota where they still account for $9.8 \%$ (NSO Malawi, ICF 2017). Whilst it is understandable, and in some appears sensible, that the Malawi Government to have to have excluded TBAs for intrapartum care, on the basis of global evidence and recommendations, it also seems that assessing whether women are 
82 able to access, or indeed wish to access, skilled birth attendance requires more than 83 "playing the numbers game"(Storeng, Behague 2014).

84

Those issues of uneven levels of skilled birth attendance and unassisted deliveries prompted us to examine more closely community actors' perceptions of the implementation of the 2007

87 Community Policy in Malawi. Doing so revealed some perceived effects on women's decision-making and delivery care-seeking behaviours in rural areas of Malawi. Unlike most analyses of health policy implementation, the study did not focus on local implementers' views on health policy dissemination and negotiation (Scott et al. 2012, George 2009) but rather focused on the perceptions of those at the receiving end of a policy that has affected their lives - women, men, and TBAs-. We focused on rural areas because this is not only where most births occur, but also where women are the poorest, the most out of reach of health services, and sadly also where most maternal deaths take place (NSO Malawi, ICF 2017).

\section{Methods}

\section{Study design}

This qualitative study used the constructivist grounded theory methodology developed by Charmaz (2006). Using this methodology, we developed a model which adds to the literature by revealing the complex interactions between community actors' perceptions of the 2007 101 Community Policy, and other social factors and determinants, which are at play in their decision making with regards to where and with whom to give birth.

\section{Study setting}


104 The data collection took place over several months in 2013 , in three districts of Central and

105 Southern Malawi: Lilongwe, Mchinji and Zomba,shown in figure 1. The latest Malawi

106 demographic and health survey showed that $50.7 \%$ of the Malawian population is living

107 belowliving below the poverty line, $94.8 \%$ of whom in rural areas (NSO Malawi, ICF 2017).

108 The Human Development Index (HDI), a çeomposite index "measuring long-term progress in

109 three basic dimensions of human development: a long and healthy life, access to knowledge

110 and a decent standard of living", places Malawi in the low-development category, ranking

$111 \quad 173$ out of a total of 188 countries (United Nations Development Programme. 2015).

112 In rural areas, most of the population survives on subsistence farming, and a greater

113 proportion of women do unpaid work on their families' farms (United Nations Development

114 Programme. 2015). With regards to the Gender Inequality Index -which reports on gender-

115 based inequalities in reproductive health, empowerment, and economic activity-Malawi ranks

116140 out of 155 countries (United Nations Development Programme. 2015).

117 -Malawi has a three-tier system of health care (health centre, district hospital, central 118 hospital) with most primary care delivered at local health centres. Over half of all deliveries 119 take place at health centres, where medical assistants are likely to be the most skilled health 120 staff, and where there is a lack of an enabling environment- e.g. dependable electricity or 121 clean water source- or comprehensive emergency obstetric care (Malawi Government122 Ministry of Health 2015). Women who need it are usually referred to district hospitals 123 (secondary level) or central hospitals( tertiary level) to receive emergency obstetric and new124 born care (NSO Malawi, ICF 2017). However staff shortages and the quality of available 125 EmONC remain major issues at Malawi hospitals (Bradley et al. 2015).

\section{Recruitment and data collection}

127 A total of 157 people participated in this study, mainly rural community actors (117), but also 128 health professionals and other stakeholders (40). Eligibility criteria, number of participants 129 and methods used for data collections are set out in table 1. Participants' views were 
130 collected through semi-structured interviews and focus group discussions_(FGDs); those 131 were conducted by the first author both in English (SBAs, Stakeholders, HSAs) and in 132 Chichewa (men, women, TBAs, VHs and some HSAs), the local language, with the help of a 133 Malawian research assistant. Purposive sampling was used to begin the data collection. 134 Thereafter, snowball sampling was used to identify additional participants (Noy 2008). 135 Finally, theoretical sampling was applied to look for deviant cases and to check the 136 properties of categories emerging from the analysis of the data. The interviews and FGDs 137 conducted in Chichewa were translated in Malawi by paid university graduates fluent in both 138 languages. A sample of the written transcription and translations of TBA and women 139 interviews and FGDs were also double-checked for accuracy by a professional translator.

140 Table 1. Eligibility criteria, description of participants and method for data collection

142 The analysis of the data collected was guided by the process indicated by Charmaz (2006). 143 Interviews and FGDs were transcribed, and translated whilst in the field, and background 144 observation notes were written about each interview. Transcripts were downloaded into the 145 NVivo software to support the analysis. Memo-writing - written notes and reflection about 146 the data- started early in the coding in the field. This was followed by focused coding, using 147 the "most significant or frequent initial codes to sort, synthesize, integrate, and organize 148 large amounts of data" (Charmaz 2006, p.46). Initial memos were later turned into more 149 analytical memos. Original codes were compared using constant comparison, a hallmark of 150 grounded theory, in order to form overarching categories. We specifically looked for 151 confirming and disconfirming data within and between transcripts and sets of actors in order 152 to test the validity of the categories. The final stages involved theoretical coding to map out 153 the relationships between the four main categories developed and to form an emerging 154 theory- the model presented in Figure 1-. 


\section{Results}

156 The model below was developed to illustrate how different contextual factors, including the perceptions of the 2007 Community Policy itself, influence the way in which rural women -

158 alongside those who support them in their community- weighed their options for delivery 159 care within the context of the implementation of this policy.

160 The model resembles a funnel as the intention is to describe a non-linear set of pathways, 161 rather than women's progress by first overcoming one barrier, then another in a sequence 162 that ultimately leads to a decision regarding their delivery care. Instead, the funnel can be 163 perceived as three-dimensional and represents a set of interrelated and overlapping 164 contextual factors (contained in the bubbles) which may all come into play at the time when 165 such complex decisions are made. There are four inter-related main categories_(in the 166 bubbles): between concordance and secret non-compliance, encountering barriers, 167 considering proximal help, and the breaking of linkages in the continuum of care (CoC). The 168 large circle around the funnel shows that the space where options are weighed and various 169 factors intertwine in the funnel is that of the 'community level', which since the advent of the 1702007 Community Policy is separated from the 'health facility level' (outside the circle). Each 171 of the categories in the model is discussed below starting from the top moving down through 172 the funnel model presented in figure 1.

Figure 1. The model 'Weighing the options for delivery care in rural Malawi' Between concordance and secret non-compliance with the Policy

175 This category was developed to account for what Long calls the "modes of rationality" which 176 operate when women make decisions regarding their delivery care. By rationality, we do not 177 refer only to the intrinsic mode of thought of individuals, but rather to what Long describes as 178 being "drawn from the stock of available discourses that form part of the cultural milieux of social practice", which "cannot be separated from the social practices of actors" (Long 2001, p.15). This category explored how what women know, what they are asked to do through the 
181 policy, and what they believe, interact, to lead to a number of actions and positions regarding 182 the 2007 Community Policy recommendations. We labelled these positions as concordance, 183 compliance, and secret non-compliance. The terms were innovatively applied here to policy 184 analysis, and are derived from the discourse related to medicine-taking (Horne et al. 2005, 185 Pound et al. 2005). Concordance usually refers to a form of agreement between doctor and 186 patient about the prescription to take (Pound et al. 2005, p.134); compliance refers to "the extent to which the patient's behaviour matches the prescriber's recommendations" (Horne et al. 2005, p.12). We used the term 'concordance' to describe the level of agreement between SBAs, women, and other community actors, with the intent of the 2007 Community Policy, which was to make deliveries safe, and keep mothers as well as babies alive. The terms 'compliance' and 'secret non-compliance' were used to describe some of the decisions made by women in response to the new constraints brought by the policy.

The 2007 Community Policy was prescriptive and demanded that women make "appropriate decisions and take timely actions" (Republic of Malawi Ministry of Health 2007a, p.3)

This quote betrayed a policy perceived as imposed from above, through the authorities. It was also seen as punitive because it was backed up by potential sanctions (fines) for noncompliance with facility delivery, imposed by village headpersons and chiefs through local 
and their babies are born alive" (Republic of Malawi Ministry of Health 2007b, p.6). This safety was meant to be guaranteed by the hospital and the authoritative biomedical

knowledge of skilled birth attendants, who can deal with complications. By contrast the Government claimed that such safety could not be guaranteed by TBAs, owing to their insufficient skills and unsuitable delivery environments. As a result, TBAs' traditional knowledge in childbirth became devalued in the eyes of the public. So much so that our study revealed that there is now concordance between policymakers, health professionals and women's belief in the safety of skilled birth attendance and skilled birth attendants' authoritative biomedical knowledge:

(Participant 1) TBAs help, but here [at hospital] they can increase the birth canal [ when there is obstructed labour] and then suture. Can TBAs suture?

(Participant 2) ....here if there is need for an operation, caesarean section, they take you for that, while at the TBAs they will just be looking at you.

(Women, focus group W01)

However, women's concordance with the concept of the safety of skilled birth attendance does not necessarily ensure their compliance with the policy recommendation to deliver at a health facility, for a number of reasons.

First, the data showed that women perceived the risks involved in pregnancy and childbirth differently to that of skilled birth attendants. Whilst skilled birth attendants spoke at length about the risks of severe pregnancy and labour complications in as something to be anticipated, and managed at facilities, women perceived childbirth complications rather as unpredictable dangers, to be dealt with as and if they arose:

It's just the way things happen when the birth canal is narrow [obstructed labour], ...So it is incumbent upon those who carried the patient to find a means of transport to take her up to the hospital to be assessed for possible complications.

(Woman, focus group W05)

For that reason, some women stayed at home or delayed going to hospital, and thus failed to comply with delivering at facilities. 
239 A second reason for their non-compliance was that, despite the dominance of authoritative 240 biomedical knowledge in childbirth, other knowledge about childbirth persisted. For instance, 241 some women felt that SBAs at facilities appeared to do their work 'by the clock', telling them 242 to wait for their 'time' to deliver. Yet women, particularly multiparous, had other embodied 243 knowledge of their delivery time, which tended to conflict with that of -SBAs:

at the hospital...with one baby, when I went in, when my time was due, they chased me and sent me out saying that it was not yet time. When I went back in, they did the same thing, they said 'go outside', it was hard for me. Then I forced my way in and immediately, the baby was born (Woman, focus group W06)

This competing knowledge led to miscommunications between women and SBAs. Some women reported feeling ignored, mistreated, or neglected. This made them reluctant to come back to the facility for their next delivery and to comply with the 2007 Community Policy recommendations. For some women, instead of coming back to the facilities, they turned to TBAs in secret for help, knowing that this went against the policy recommendations and that they could be penalised. This was partly because, despite the fact that TBAs have been found lacking in respect of the professional technical care required to deal with childbirth complications, they have been praised and sought after for the quality of the emotional support and continuous labour support they provide to women (Ryan et al. 2015). This aspect of TBA care has been cited in studies as a reason for women continuing to deliver with them, even where skilled care is available at health facilities and even when women believe that facilities are safer overall (Kumbani et al. 2013). In our study, women often compared TBA and SBA levels of interpersonal care:

the azamba [TBA] will hold your back [sitting behind the pregnant woman] as a way of helping you to give birth. In that way you feel good, you don't face any problem because they help you. But when you go to hospital, they tell to lie on a bed. So, when you lie on the bed, the nurse will just sit [ away at her desk]and only urge you, "Push! Push!" That makes you regret coming to hospital and wish you had gone to azamba's (Woman, focus group W05) 
270 However, 'secret non-compliance' with the 2007 Community Policy recommendations also

271 happened for other reasons, as this TBA pointed out:

272

273

274

275

276

277

278

280

281

282

283

284

285

286

287

288

289

290

291

292

293

294

295

296

297

298

299 we have been stopped and we are now referring them to the hospital...but they always come to us, pleading us "sorry, sorry, sorry, we don't have a bicycle, we don't have anything, just do it in a secret, such that other people don't know that we do deliver here" (TBA, interview TBA08)

This quote refers to several other barriers women encountered when weighing their options about where to deliver their babies. Those were captured by the category encountering barriers, discussed below.

\section{Encountering barriers}

Barriers of poverty, lack of transport, distance and costs are significant and well known barriers for women in accessing skilled birth attendance (Bohren et al. 2014, Gabrysch, Campbell 2009). In our study, women in all focus groups expressed this:

The hospital is good but when your time has come, for you to go to the hospital some are delivering on the way, because the hospital is far, and we do not have a reliable bicycle for us to use and rush to the hospital (Woman, focus group W04)

The unavailability of transport to go to hospital is often described as caused by poverty itself, (Oyerinde et al. 2012, Pfeiffer, Mwaipopo 2013). However, our study revealed in more detail how poverty may prevent compliance with skilled birth attendance in other ways. Some women explained that they were so poor that they simply could not afford to purchase the items they were asked to bring with them to facilities for their delivery:

It is just because some people are poor, because if you want to go to the hospital you need to have food, cloths, yet the husband is not working, and you don't have anything to take to the hospital. So the woman thinks that she could not be comfortable at the hospital seeing other women having such things and not her, so she says 'it's better I could just stay at home when it is my time "("Woman, focus group W07)

These particular barriers require more in-depth investigation and do need to be addressed.

Furthermore, besides those barriers of poverty and lack of transport, the study revealed that some women's experiences of disrespectful and abusive (D\&A) care in childbirth at health 
300 facilities may also be significant in their not complying with the 2007 Community Policy

301 recommendations.

302 Bohren et al. have defined D\&A care in childbirth as ranging from physical and verbal abuse 303 to a " poor rapport between women and providers" and health systems constraints (2015, 304 p.7). A growing literature on the subject has demonstrated the potential impact of these 305 behaviours on women's childbirth care satisfaction, including in Malawi (Bradley et al. 2016).

Our data revealed such instances of D\&A care, particularly neglect and verbal abuse:

307

308

309

310

311

312

313

314

315

316

317

318

\begin{abstract}
you complain, because of the way you are, what you are feeling [the pains of labour]. Sometimes doctors don't talk with respect, they despise us. I experienced that with my first-born child, if you ask "I want to go to the toilet", instead of telling you nicely they just say "you just go". Then, if you go, you just discover that the baby has fallen into a pit latrine ...that's when they call us and begin to shout at us saying "you say we kill your babies, yet you are killing the babies yourselves" (Woman, focus group W01)
\end{abstract}

It is not difficult to imagine how such personal experiences, when added to other extrinsic barriers, may become what we called 'the tipping point' towards non-compliance, that is a further reason for women to consider other proximal help instead of skilled birth attendance.

\title{
Considering proximal help
}

We defined the category considering proximal help as not going to a facility to deliver but instead giving birth with a relative at home, or at a nearby TBA in secret. Secret deliveries by TBAs have placed them 'between a rock and a hard place', where they feel on the one hand that they want to support women in their community, but on the other are uncomfortable about defying the ban and incurring sanctions:

it just happens, we just see a person who is in need of help coming, not that we really desire that we should be doing this job, but someone comescomes, and they need your help, how do you deny them? That is why we do it (trained TBA, interview TBA05

$\underline{\text { TBAs did feel such pressures, with some even refusing to help women and redirecting them }}$

to facilities as they were meant to. Women also felt torn, as they knew that by calling on a 
330 secret' could have consequences, not least if severe complications arose at home or with a 331 TBA. At times, the baby or the mother may die before or as they reach the facility, other 332 times they may survive but with severe morbidity, as has happened in many low income 333 countries (Geller et al. 2018). In order to prevent such tragedies, a continuum of care (CoC) 334 between village and health facility would ideally be required. This continuum of care 335 depends on strong links between home, community and facility care as well as between 336 antenatal, delivery and postnatal care (Kikuchi et al. 2015). Its importance has been stressed 337 by WHO and the Partnership for Maternal, Newborn and Child Health (2010). However, our 338 study showed that the 2007 Community Policy has instead led to a breaking of linkages in 339 the continuum of care between community and health facility.

\section{The breaking of linkages in the continuum of care}

341 This fourth main category in our model is visually represented by the black wall-like circle 342 around the funnel diagram (Figure 1), because it represents another barrier, generated by 343 the policy itself and the significant gap in CoC it created between community and health 344 facility levels. The term 'breaking' is used here to imply that linkages did exist prior to the 345 advent of the 2007 Community Policy. Indeed, there were links which had developed over 346 decades of TBA training by SBAs, as well as through ongoing supervision and meetings 347 (Wendland 2015), prior to the ban. However the 2007 Community Policy side-lined TBAS 348 and gave the role of supporting the $\mathrm{CoC}$ in the community to health surveillance assistants 349 (HSAs) and to village headpersons (VHs). The policy stated that those would now 350 coordinate" transport for referrals, including acquisition of bicycle ambulances [and] 351 supervising management of bicycle ambulances in readiness for referral of patients to health 352 facility" (Republic of Malawi Ministry of Health 2007a).

353 However, neither of those links have significantly materialised. The first reason is that HSAs 354 - on whom many tasks have been shifted - are not trained to conduct deliveries; Secondly 355 VHs are often unable to provide or pay for transport for referrals, and lack the knowledge 
356 required to recognise childbirth complications that require referral. Furthermore, although VH 357 are very influential, they are now perceived by community members, more as policy 358 enforcers (in charge of delivering fines to women who fail to deliver at health facilities), rather 359 than referral enablers. This relationship is not conducive to building the trust and good 360 communications between $\mathrm{VH}$ and community members that is generally seen as contributing 361 to an effective continuum of care (Gilson 2003).

363 The breaking of linkages between community and health facility has had serious 364 consequences. With no TBAs allowed to help since the advent of the 2007 Community 365 Policy, and no money or transport to access skilled birth attendance, some rural women 366 have opted for home births, sometimes with no one present. Other women have made their 367 way to the facilities late, after exhausting other options, and have eventually birthed 'on the 368 way', before arrival, in unhygienic and unsafe conditions(Banda 2013). It is difficult to say 369 how often this has occurred, but the estimated current national percentage of births with no 370 one present is $2 \%$ and that of births assisted by relatives or friends $4 \%$ (NSO Malawi, ICF 371 2017). We can also assume that births before arrival are underreported owing to the 372 sanctions that may be incurred by women if they report those. Orobaton, et al (2016) as well 373 as Banda (2013) have recently suggested like us that these births outside the facility are 374 more common in rural areas.

\section{Positionality and limitations}

376 The first author's positionality (white educated female), which in rural Malawi can be equated

377 to being a 'doctor' may have mattered in the conduct of some of the interviews and FGDs.

378 However, this was offset by conducting interviews in the local language, with a local 379 research assistant, and by spending ample time explaining to participants the position of the 380 first author as a social scientist interested in people's lived experience of the 2007 381 Community Policy. 
382 A challenge for the data coding and analysis was the high number of the interviews and 383 FGDs conducted and the diversity of participants. This was partly overcome by the decision

384 to bring key actors to the fore in the analysis (such as TBAs and women), and using other 385 actors (men, $\mathrm{VH}$ ) as counterpoints. In this study, as in any qualitative study, alternative 386 interpretive accounts could be drawn from the data (Charmaz 2006). By focusing particularly 387 on the accounts of women and TBAs we developed categories further and built the model 388 best suited to account for the perceptions of those at the receiving end of a policy that has 389 affected the way in which they weigh their options for delivery care.

\section{Discussion and conclusion}

391 The grounded theory model presented in Figure 1 accounts for a web of contextual factors 392 which affects the way in which rural women, and those who support them, weigh their 393 options and make decisions regarding delivery care within the context of the implementation 394 of the 2007 Community Policy. The concepts of concordance and compliance associated 395 with medicine-taking were innovatively used to reveal the concordance between rural 396 women and policymakers about the intent of the policy, whilst explaining women's varying 397 degrees of compliance with policy recommendations.

398 We showed that women's decisions are often motivated not simply by their awareness of 399 what they must do (follow policy recommendations or face sanctions), but also by what they 400 believe (their own embodied knowledge of childbirth, and their own perceptions of childbirth 401 risks). The model also shows how other external barriers, including geographical and 402 economic barriers, interact with those decisions, as do previous experiences of disrespectful 403 and abusive care at facilities.

404 This study revealed that although the 2007 Community Policy implementation did not create 405 such barriers, it aggravated their impact for rural women. For instance, while the policy is not 406 the reason why women lack transport or funds to attend at facilities, it intentionally removed 407 the access to nearby TBAs, leaving women in greater difficulty and with fewer options in the 408 context of broken linkages between communities and health facilities. The mix of intrinsic 
409 and extrinsic factors presented in the model, and their interconnectedness, potentially

410 applies to other areas of maternal health policy implementation analysis particularly in sub-

411 Saharan Africa. The model could be applied to understanding how women perceive and

412 comply with antenatal care policies, or with policies promoting birth preparedness (including

413 those recommending the use of waiting homes),

415 The responsibility to provide accessible, affordable, and acceptable quality delivery care to 416 all women in Malawi falls on the Government. In the past decade Malawi has invested and 417 showed a strong commitment in this area and has made laudable progress (UNICEF., WHO. 418 2015). However, with regards to the 2007 Community Policy implementation, the time has 419 come to ask, "what are the welfare implications of a ban on informal attendants and is this a 420 good policy?" (Godlonton, Okeke 2016, p.125). We argue that a policy which focuses 421 exclusively on attaining maximum skilled birth attendance rates, could be considered short422 sighted, particularly as skilled birth attendants and comprehensive emergency obstetric 423 services remain lacking in Malawian facilities (Kongnyuy et al. 2009, Leslie et al. 2016). 424 Policies such as this are often the result of global policy transfer, imposed top-down and do 425 not always take into account local realities and contexts (Storeng, Behague 2014, Behague 426 et al. 2009). We contend that the 2007 Community Policy could be adapted to suit rural 427 realities, without compromising the intent to keep all women and babies safe. As women 428 from remote rural areas are now strongly asked to travel to facilities for their deliveries, 429 transportation vouchers could be provided to support them, as has been done successfully 430 in Uganda (United Nations. 2015). Furthermore banned TBAs could be incentivised to act 431 as birth companions, accompanying pregnant women to give birth at hospitals ensuring their 432 safety along the way, as has been successfully done elsewhere (Tomedi et al. 2015, Pyone 433 et al. 2014). In rural areas, TBAs could be trained, to perform non-delivery related tasks as 434 has been shown to work well recently in other sub-Saharan African countries (Gill et al. 435 2011, Yeboah-Antwi et al. 2014, Hamela et al. 2014, Brennan et al. 2014). This may ensure 
436 that the link to communities is maintained in the $\mathrm{CoC}$, and that TBAs remain allies rather 437 than enemies in the fight for safe deliveries.

439 A recent Lancet series reviewed the progress made regarding maternal mortality 440 reduction in the past decade (Campbell et al. 2016). It stressed that progress to end 441 preventable deaths has remained unequal across regions as well as sub-nationally (often 442 along rural/urban divides). As a result, some have argued the need to take more of "a view 443 from the ground" (Freedman 2016, p.1) when it comes to assessing the impact of globally 444 formulated policies. This study offers such a view from the ground, which could help address 445 those issues, and help devise more locally adapted solutions. As currently implemented, it 446 may be difficult to argue that the 2007 Community Policy has been effective, simply because 447 the maternal mortality ratio is falling overall. The Government of Malawi has a duty of care to 448 all mothers and babies, whether in urban or rural areas, whether well-off or poor. Social 449 accountability does matter in policy making and, for this to happen, it needs to strive towards 450 more inclusive, collaborative and contextualized solutions. 


\section{References}

BAILEY, P., SZÁSZDI, J. and GLOVER, L., 2002. Obstetric complications: does training traditional birth attendants make a difference? Revista Panamericana De Salud Pública, vol. 11, no. 1.

BANDA, E.C., 2013. Stakeholders' perceptions of the changing role of traditional birth attendants in the rural areas of central Wets zone, Malawi: a mixed methods study. PhD ed. University of the Witwatersrand.

BEHAGUE, D. and STORENG, K., 2013. Pragmatic politics and epistemological diversity: the contested and authoritative uses of historical evidence in the Safe Motherhood Initiative. Evidence \& Policy: A Journal of Research, Debate and Practice, vol. 9, no. 1, pp. 65-85.

BEHAGUE, D., TAWIAH, C., ROSATO, M., SOME, T. and MORRISON, J., 2009. Evidencebased policy-making: the implications of globally-applicable research for context-specific problem-solving in developing countries. Social Science \& Medicine, 11/15, vol. 69, no. 10, pp. 1539-1546 ISSN 0277-9536.

BHUTTA, Z.A., CHOPRA, M., AXELSON, H., BERMAN, P., BOERMA, T., BRYCE, J., BUSTREO, F., CAVAGNERO, E., COMETTO, G., DAELMANS, B., DE FRANCISCO, A., FOGSTAD, H., GUPTA, N., LASKI, L., LAWN, J., MALIQI, B., MASON, E., PITT, C., REQUEJO, J., STARRS, A., VICTORA, C.G. and WARDLAW, T., 2010. Countdown to 2015 decade report (2000-10): taking stock of maternal, newborn, and child survival. Lancet, 06/05, vol. 375, no. 9730, pp. 2032-2044 ISSN 1474-547X.

BOHREN, M., HUNTER, E., MUNTHE-KAAS, H., SOUZA, J., VOGEL, J. and GÜLMEZOGLU, A., 2014. Facilitators and barriers to facility-based delivery in low- and middle-income countries: a qualitative evidence synthesis. Reproductive Health, vol. 11, no. 71, pp. 1-17.

BOHREN, M., VOGEL, J., HUNTER, E., LUTSIV, O., MAKH, S., SOUZA, J., AGUIAR, C., SARAIVA CONEGLIAN, F., DINIZ, A., TUNÇALP, O., JAVADI, D., OLADAPO, O., KHOSLA, R., HINDIN, M. and GÜLMEZOGLU, A., 2015. The Mistreatment of Women during Childbirth in Health Facilities Globally: A Mixed-Methods. PLoS Medicine, vol. 12, no. 6-e.

BRADLEY, S., KAMWENDO, F., CHIPETA, E., CHIMWAZA, W., DE PINHO, H. and MCAULIFFE, E., 2015. Too few staff, too many patients: a qualitative study of the impact on obstetric care providers and on quality of care in Malawi. BMC Pregnancy and Childbirth, vol. 15, no. 65 - PMC. ISSN - 1471-2393. DOI - 10.1186/s12884-015-0492-5.

BRADLEY, S., MCCOURT, C., RAYMENT, J. and PARMAR, D., 2016. Disrespectful intrapartum care during facility-based delivery in sub-Saharan Africa: A qualitative systematic review and thematic synthesis of women's perceptions and experiences. Social Science \& Medicine, 11, vol. 169, pp. 157-170 ISSN 0277-9536. DOI http://dx.doi.org/10.1016/j.socscimed.2016.09.039. 
BRENNAN, A.T., THEA, D.M., SEMRAU, K., GOGGIN, C., SCOTT, N., PILINGANA, P., BOTHA, B., MAZIMBA, A., HAMOMBA, L. and SEIDENBERG, P., 2014. In-home HIV testing and nevirapine dosing by traditional birth attendants in rural Zambia: a feasibility study. Journal of Midwifery and Women's Health, vol. 59, no. 2, pp. 198-204.

CAMPBELL, O.M., CALVERT, C., TESTA, A., STREHLOW, M., BENOVA, L., KEYES, E., DONNAY, F., MACLEOD, D., GABRYSCH, S., RONG, L., RONSMANS, C., SADRUDDIN, S., KOBLINSKY, M. and BAILEY, P., 2016. The scale, scope, coverage, and capability of childbirth care. The Lancet, vol. 388, no. 10056, pp. 2193-2208 ISSN 0140-6736. DOI http://dx.doi.org/10.1016/S0140-6736(16)31528-8.

CHARMAZ, K., 2006. Constructing grounded theory:A practical guide through qualitative analysis. London: SAGE ISBN 0761973524 (hbk.).

COLBOURN, T., LEWYCKA, S., NAMBIAR, B., ANWAR, I...P.,A. and MHANGO, C., 2013. Maternal mortality in Malawi, 1977-2012. British Medical Journal, vol. 3.

DE BROUWERE, V. and VAN LERBERGHE, W., 2001. Safe Motherhood Strategies : a Review of the Evidence. V. DE BROUWERE and W. VAN LERBERGHE eds., Studies in Health Services Organisation \& Policy, 17 ed.ITG Press.

FREEDMAN, L.P., 2016. Implementation and aspiration gaps: whose view counts?. The Lancet, 11/23, vol. 388, no. 10056, pp. 2068-2069 ISSN 0140-6736.

GABRYSCH, S. and CAMPBELL, O., 2009. Still too far to walk: Literature review of the determinants of delivery service use. BMC Pregnancy and Childbirth, vol. 9, no. 34.

GELLER, S.E., KOCH, A.R., GARLAND, C.E., MACDONALD, E.J., STOREY, F. and LAWTON, B., 2018. A global view of severe maternal morbidity: moving beyond maternal mortality. Reproductive Health, 06/22, vol. 15, no. 1, pp. 98 ISSN 1742-4755. DOI 10.1186/s12978-018-0527-2.

GEORGE, A., 2009. 'By papers and pens, you can only do so much': views about accountability and human resource management from Indian government health administrators and workers. The International Journal of Health Planning and Management, 07/01; 2018/05, vol. 24, no. 3, pp. 205-224 ISSN 0749-6753. DOI 10.1002/hpm.986.

GILL, C.J., PHIRI-MAZALA, G., GUUERINA, N.G., KASIMBA, J., MULENGA, C. and MACLEOD, W.B., 2011. Effect of training traditional birth attendants on neonatal mortality (Lufwanyama Neonatal Survival Project): randomized controlled study. Bmj, vol. 342 DOI 10.1136/bmj.d346.

GILSON, L., 2003. Trust and the development of health care as a social institution. Social Science \& Medicine, 4, vol. 56, no. 7, pp. 1453-1468 ISSN 0277-9536. DOI http://dx.doi.org/10.1016/S0277-9536(02)00142-9.

GODLONTON, S. and OKEKE, E.N., 2016. Does a ban on informal health providers save lives? Evidence from Malawi. Journal of Development Economics, 1, vol. 118, pp. 112-132 ISSN 0304-3878. DOI http://dx.doi.org/10.1016/j.jdeveco.2015.09.001.

HAMELA, G., KABONDO, C., TEMBO, T., ZIMBA, C., KAMANGA, E., MOFOLO, I., BULLA, B., SELLERS, C., LEE, C., MARTINSON, F., HOFFMAN, I., VAN DER HOST, C. and HOSSEINIPOUR, M., 2014. Evaluating the benefits of incorporating traditional birth 
attendants in HIV Prevention of Mother to Child Transmission service delivery in Lilongwe, Malawi. African Journal of Reproductive Health, vol. 18, no. 1, pp. 17.

HORNE, R., WEINMAN, J., BARBER, N., ELLIOTT, R.A. and MORGAN, M., 2005. Concordance, adherence and compliance in medicine taking. National Institute for Health Research (NIHR) Service Delivery and Organisation (SDO) Programme.

HUSSEIN, J. and CLAPHAM, S., 2005. Message in a bottle: sinking in a sea of safe motherhood concepts. Health Policy (Amsterdam, Netherlands), 09/08, vol. 73, no. 3, pp. 294-302 ISSN 0168-8510.

JORDAN, B., 1997. Authoritative knowledge and Its construction. In: R.E. DAVIS-FLOYD and C.F. SARGENT eds., Childbirth and authoritative knowledge Berkeley, London: University of California Press, pp. 55-79 ISBN 0520206258.

KIKUCHI, K., ANSAH, E.K., O., S., E., Y., YASUOKA, J., NANISHI, K., SHIBANUMA, A., GYAPONG, M., OWUSU-AGYEI, S., ODURO, A.R., ASARE, G.Q., HODGSON, A., JIMBA, M. and Ghana EMBRACE Implementation Research Project Team, 2015. Effective Linkages of Continuum of Care for Improving Neonatal, Perinatal, and Maternal Mortality: A Systematic Review and Meta-Analysis. PLoS ONE, 09/09, vol. 10, no. 9, pp. e0139288 PMC. ISSN 1932-6203. DOI 10.1371/journal.pone.0139288.

KONGNYUY, E.J., HOFMAN, J., MLAVA, G., MHANGO, C. and VAN DEN BROEK, N., 2009. Availability, utilisation and quality of basic and comprehensive emergency obstetric care services in Malawi. Maternal and Child Health Journal, 09, vol. 13, no. 5, pp. 687-694 ISSN 1573-6628.

KUMBANI, L., BJUNE, G., CHIRWA, E., MALATA, A. and ODLAND, J.O., 2013. Why some women fail to give birth at health facilities: a qualitative study of women's perceptions of perinatal care from rural Southern Malawi. Reproductive Health, vol. 10 DOI 10.1186/17424755-10-9.

LESLIE, H.H., FINK, G., NSONA, H. and KRUK, M.E., 2016. Obstetric Facility Quality and Newborn Mortality in Malawi: A Cross-Sectional Study. PLoS Med, 10/18, vol. 13, no. 10, pp. e1002151.

LONG, N., 2001. Development Sociology: Actor Perspectives. London: Routledge.

Malawi Government-Ministry of Health., 2015. Malawi Emergency Obstetric and Newborn Care Needs Assessment.

MILLER, S., SLOAN, N.L., WINIKOFF, B., LANGER, A. and FIKREE, F.F., 2003. Where is the "E' in $\mathrm{MCH}$ ? The need for an evidence-based approach in safe motherhood. Journal of Midwifery \& Women's Health, 2003, vol. 48, no. 1, pp. 10-18 ISSN 1526-9523.

NOY, C., 2008. Sampling Knowledge: The Hermeneutics of Snowball Sampling in Qualitative Research. Journal International Journal of Social Research Methodology, vol. 11, no. 4 , pp. 327.

NSO Malawi and ICF., 2017. Malawi Demographic and Health Survey 2015-16. NSO and ICF. 
OROBATON, N., AUSTIN, A., FAPOHUNDA, B., ABEGUNDE, D. and OMO, K., 2016. Mapping the prevalence and sociodemographic characteristics of women who deliver alone: evidence from demographic and health surveys from 80 Countries. Global Health Science Pract, vol. 4 DOI 10.9745/GHSP-D-15-00261.

OYERINDE, K., HARDING, Y., AMARA, P., GARBRAH-AIDOO, N., KANU, R. and OULARE, M., 2012. Barriers to uptake of emergency obstetric and newborn care services in Sierra Leone: a qualitative study. Community Med Health Educ, vol. 2.

PFEIFFER, C. and MWAIPOPO, R., 2013. Delivering at home or in a health facility? healthseeking behaviour of women and the role of traditional birth attendants in Tanzania. BMC Pregnancy and Childbirth, vol. 13, pp. n/a-55 ProQuest Family Health. ISSN 14712393. DOI http://dx.doi.org/10.1186/1471-2393-13-55.

POUND, P., BRITTEN, N., MORGAN, M., YARDLEY, L., POPE, C., DAKER-WHITE, G. and CAMPBELL, R., 2005. Resisting medicines: a synthesis of qualitative studies of medicine taking. Social Science \& Medicine, 07, vol. 61, no. 1, pp. 133-155 ISSN 0277-9536.

PYONE, T., ADAJI, S., MADAJ, B., WOLDETSADIK, T. and VAN DEN BROEK, N., 2014. Changing the role of the traditional birth attendant in Somaliland. International Journal of Gynecology \& Obstetrics, vol. 127, no. 1, pp. 41-46 ISSN 0020-7292. DOI http://dx.doi.org/10.1016/j.ijgo.2014.04.009.

Republic of Malawi Ministry of Health., 2012. Road Map for Accelerating the Reduction of Maternal and Neonatal Mortality and Morbidity in Malawi. Republic of Malawi-Ministry of Health.

Republic of Malawi Ministry of Health., 2007a. Guidelines for Community Initiatives for Reproductive Health.

Republic of Malawi Ministry of Health., 2007b. Road Map for accelerating the reduction of maternal and neonatal mortality and morbidity in Malawi. Third Revised Version ed. Republic of Malawi- Ministry of Health.

Republic of Malawi Ministry of Health., 2006. Assessment of future roles of traditional birth attendants (TBAs) in maternal and neonatal health in Malawi. Republic of Malawi Ministry of Health;.

RYAN, J., HAMELA, G., CHOME, N., KABONDO, C., HOSSEINIPOUR, M. and TANG, J., 2015. Experiences and beliefs of Malawian women who have delivered with a traditional birth attendant. International Journal of Gynecology \& Obstetrics, 4, vol. 129, no. 1, pp. 3841 ISSN 0020-7292. DOI http://dx.doi.org/10.1016/j.ijgo.2014.11.006.

SCOTT, V., MATHEWS, V. and GILSON, L., 2012. Constraints to implementing an equitypromoting staff allocation policy: understanding mid-level managers' and nurses' perspectives affecting implementation in South Africa. Health Policy and Planning, March 01, vol. 27, no. 2, pp. 138-146 DOI 10.1093/heapol/czr020.

SIBLEY, L.M., SIPE, T.A. and BARRY, D., 2012. Traditional birth attendant training for improving health behaviours and pregnancy outcomes. Cochrane Database of Systematic Reviews, no. 8. 
SIBLEY, L.M., SIPE, T.A. and KOBLINSKY, M.A., 2004. Does traditional birth attendant training improve referral of women with obstetric complications: a review of the evidence. Social Science \& Medicine, vol. 59, no. 8, pp. 1757-1768 ISSN 0277-9536.

SMITH, J.B., COLEMAN, N.A., FORTNEY, J.A., JOHNSON, J.D., BLUMHAGEN, D.W. and GREY, T.W., 2000. The impact of traditional birth attendant training on delivery complications in Ghana. Health Policy and Planning, 09, vol. 15, no. 3, pp. 326-331 ISSN 0268-1080.

SMITH, V., DEVANE, D. and MURPHY-LAWLESS, J., 2012. Risk in Maternity Care: A Concept Analysis. International Journal of Childbirth, vol. 2, no. 2, pp. 126-135.

STORENG, K. and BEHAGUE, D., 2014. "Playing the numbers game": evidence-based advocacy and the technocratic narrowing of the Safe Motherhood Initiative. Medical Anthropology Quarterly, vol. 28, no. 2, pp. 260-279.

The Partnership for Maternal, Newborn and Child Health., 2010. PMNCH Knowledge Summary \#02 Enable the Continuum of Care.

TOMEDI, A., STROUD, S., RUIZ MAYA, T., PLAMAN, C. and MWANTHI, M.A., 2015. From home deliveries to health care facilities: establishing a traditional birth attendant referral program in Kenya. . Journal of Health, Population and Nutrition, vol. 33, no. 6.

UNICEF. and WHO., 2015. Countdown to 2015- Maternal, Newborn and child survival: A Decade of Tracking Progress for Maternal, Newborn and Child Survival-The 2015 Report. WHO.

United Nations., 2015. Saving Lives, Protecting Futures: An Every Woman Every Child Progress Report.

WENDLAND, C. Learning from the aftermath: the rise and fall of birth workers at the boundary in Malawi (orally presented paper)Anonymous MAGIC 2015- Anthropology and Global Health: interrogating theory, policy and practice (9-11 September 2015, University of Sussex), 2015.

WHO, 1999. Reduction of maternal mortality. A joint WHO/UNFPA/UNICEF/World Bank Statement.

WHO., 1979. Traditional birth attendants: a field guide to their training, evaluation and articulation with health services. WHO.

WHO., UNICEF., UNFPA., The World Bank. and United Nations Population Division., 2015. Trends in Maternal Mortality: 1990 to 2015- Estimates by WHO, UNICEF, UNFPA, World Bank Group and the United Nations Population Division. WHO.

WHO, UNFPA, UNICEF, ICM, ICN, FIGO and IPA., 2018. Definition of skilled health personnel providing care during childbirth: the 2018 joint statement by WHO, UNFPA, UNICEF, ICM, ICN, FIGO, IPA. World Health Organisation;.

YEBOAH-ANTWI, K., HAMER, D.H., SEMRAU, K., WALTENSPERGER, K.Z., SNETROPLEWMAN, G., KAMBIKAMBI, C., SAKALA, A., FILUMBA, S., SICHAMBA, B. and MARSH, D.R., 2014. Can a community health worker and a trained traditional birth attendant work as 
a team to deliver child health interventions in rural Zambia?. BMC Health Services Research, vol. 14, no. 1, pp. 1-9 ISSN 1472-6963. DOI 10.1186/s12913-014-0516-2. 


\begin{tabular}{|c|c|c|c|c|}
\hline $\begin{array}{l}\text { Participant } \\
\text { Type }\end{array}$ & Number & $\begin{array}{l}\text { Inclusion and exclusion } \\
\text { criteria }\end{array}$ & $\begin{array}{l}\text { Description of } \\
\text { participants }\end{array}$ & $\begin{array}{l}\text { Method of } \\
\text { data } \\
\text { collection }\end{array}$ \\
\hline $\begin{array}{l}\text { Traditional } \\
\text { Birth } \\
\text { Attendants } \\
\text { (TBA) }\end{array}$ & 28 & $\begin{array}{l}\text { Self-identified as a TBA } \\
\text { (whether family, trained or } \\
\text { untrained TBA, or } \\
\text { TBA/herbalists). } \\
\text { Exclusion criteria: TBAs } \\
\text { who had practiced for less } \\
\text { than a year. }\end{array}$ & $\begin{array}{l}\text { TBAs who participated } \\
\text { were mostly older* } \\
\text { women, who had } \\
\text { performed deliveries- } \\
\text { on average } 10 \text { or } 15 \\
\text { per month- in their } \\
\text { surrounding areas } \\
\text { prior to the TBA ban. } \\
\text { ( In rural Malawi it is } \\
\text { common for village } \\
\text { people not to know } \\
\text { their exact birth date, } \\
\text { these TBAs seemed to } \\
\text { be between } 50 \text { and } \\
70+\text { years old) }\end{array}$ & $\begin{array}{l}14 \text { Interviews } \\
\text { and } 2 \text { focus } \\
\text { group } \\
\text { discussion } \\
\text { (FGDs) }\end{array}$ \\
\hline $\begin{array}{l}\text { Skilled Birth } \\
\text { Attendants } \\
\text { (SBA) }\end{array}$ & 19 & $\begin{array}{l}\text { Nurse midwife technician, } \\
\text { doctor or obstetrician, } \\
\text { community midwife } \\
\text { technician, community } \\
\text { midwife assistant or clinical } \\
\text { officers; practicing in either } \\
\text { rural health centres or } \\
\text { district hospitals. } \\
\text { Exclusion criteria: SBAs } \\
\text { who had practiced for less } \\
\text { than one year. }\end{array}$ & $\begin{array}{l}\text { Nurse-midwives (NM), } \\
\text { nurse midwife } \\
\text { technicians (NMT) and } \\
\text { clinical officers who } \\
\text { took part, were very } \\
\text { experienced, apart for } \\
\text { a few who had } \\
\text { qualified only a few } \\
\text { years prior. } \\
\text { They performed } \\
\text { between } 1 \text { and } 15 \\
\text { deliveries in any single } \\
\text { shift depending on } \\
\text { whether they worked } \\
\text { in a district hospital or } \\
\text { in a smaller rural } \\
\text { health centre. }\end{array}$ & 16 interviews \\
\hline Women (W) & 42 & $\begin{array}{l}\text { Adult women of } \\
\text { reproductive age with } \\
\text { experience or knowledge of } \\
\text { childbirth. } \\
\text { Exclusion criteria: women } \\
\text { younger than 18. }\end{array}$ & $\begin{array}{l}\text { ** Women who } \\
\text { participated had } \\
\text { between } 1 \text { and } 15 \\
\text { children. For most, } \\
\text { their nearest rural } \\
\text { health centre was up } \\
\text { to } 15 \mathrm{kms} \text { away or } \\
\text { more, and they had }\end{array}$ & $\begin{array}{l}7 \text { focus } \\
\text { group } \\
\text { discussions }\end{array}$ \\
\hline
\end{tabular}




\begin{tabular}{|c|c|c|c|c|}
\hline & & & $\begin{array}{l}\text { little access to any } \\
\text { transport. A large } \\
\text { proportion had } \\
\text { delivered both at TBAs } \\
\text { and SBAs in the past. } \\
\text { (** Except for the first } 2 \\
\text { focus groups in Site } 1 \text {, } \\
\text { the men and women } \\
\text { who participated in } \\
\text { focus group discussions } \\
\text { were not related, } \\
\text { although they were from } \\
\text { the same areas.) }\end{array}$ & \\
\hline Men (H) & 29 & $\begin{array}{l}\text { Adult men living in the local } \\
\text { rural area. } \\
\text { Exclusion criteria: men } \\
\text { younger than } 18 .\end{array}$ & $\begin{array}{l}\text { ** Men who } \\
\text { participated had } \\
\text { between } 1 \text { and } 15 \\
\text { children. For most, } \\
\text { their nearest rural } \\
\text { health centre was up } \\
\text { to } 15 \mathrm{kms} \text { away or } \\
\text { more, and they had } \\
\text { little access to any } \\
\text { transport. } \\
\text { (** Except for the first } 2 \\
\text { focus groups in Site } 1 \text {, } \\
\text { the men and women } \\
\text { who participated in } \\
\text { focus group discussions } \\
\text { were not related, } \\
\text { although they were from } \\
\text { the same areas.) }\end{array}$ & $\begin{array}{l}6 \text { focus } \\
\text { group } \\
\text { discussions }\end{array}$ \\
\hline $\begin{array}{l}\text { Village } \\
\text { Headperson } \\
\text { (VH) }\end{array}$ & 18 & $\begin{array}{l}\text { Adult men or women } \mathrm{VH} \\
\text { living in the local rural area. } \\
\text { Exclusion criteria: men or } \\
\text { women younger than } 18 \\
\text { (although unlikely) }\end{array}$ & $\begin{array}{l}\text { VH who participated } \\
\text { were both female and } \\
\text { male, and looked } \\
\text { mostly over } 30 \text {. }\end{array}$ & $\begin{array}{l}3 \text { interviews; } \\
3 \quad \text { focus } \\
\text { group } \\
\text { discussions }\end{array}$ \\
\hline $\begin{array}{l}\text { Health } \\
\text { Surveillance } \\
\text { Assistants } \\
\text { (HSA) }\end{array}$ & 13 & 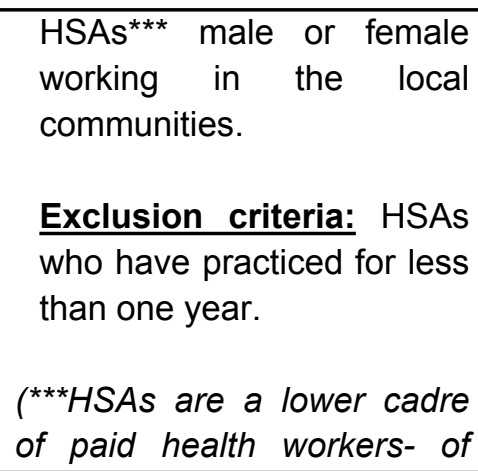 & $\begin{array}{l}\text { Male and female who } \\
\text { took part had from } \\
\text { between } 3 \text { and } 18 \text { years } \\
\text { of work experience in } \\
\text { local communities. }\end{array}$ & $\begin{array}{l}3 \text { focus group } \\
\text { discussions }\end{array}$ \\
\hline
\end{tabular}




\begin{tabular}{|c|c|c|c|c|}
\hline & & $\begin{array}{l}\text { whom there } r \text { are } \\
\text { approximately } 4500 \text { in } \\
\text { Malawi, and who are are } \\
\text { based in communities } \\
\text { (McCoy, et al., 2008). HSAs } \\
\text { act as links between } \\
\text { communities and health care } \\
\text { facilities.) }\end{array}$ & & \\
\hline $\begin{array}{l}\text { Other main } \\
\text { stakeholders } \\
\text { (OMS) }\end{array}$ & 8 & $\begin{array}{l}\text { Maternal health policy } \\
\text { officials in the Government, } \\
\text { or in regulatory bodies, } \\
\text { representatives of national } \\
\text { organisations working in } \\
\text { maternal health }\end{array}$ & $\begin{array}{l}\text { Ministry of health } \\
\text { representatives, } \\
\text { maternal and child } \\
\text { health } \\
\text { representatives, } \\
\text { academics }\end{array}$ & 8 interviews \\
\hline TOTAL & 157 & & & \\
\hline
\end{tabular}




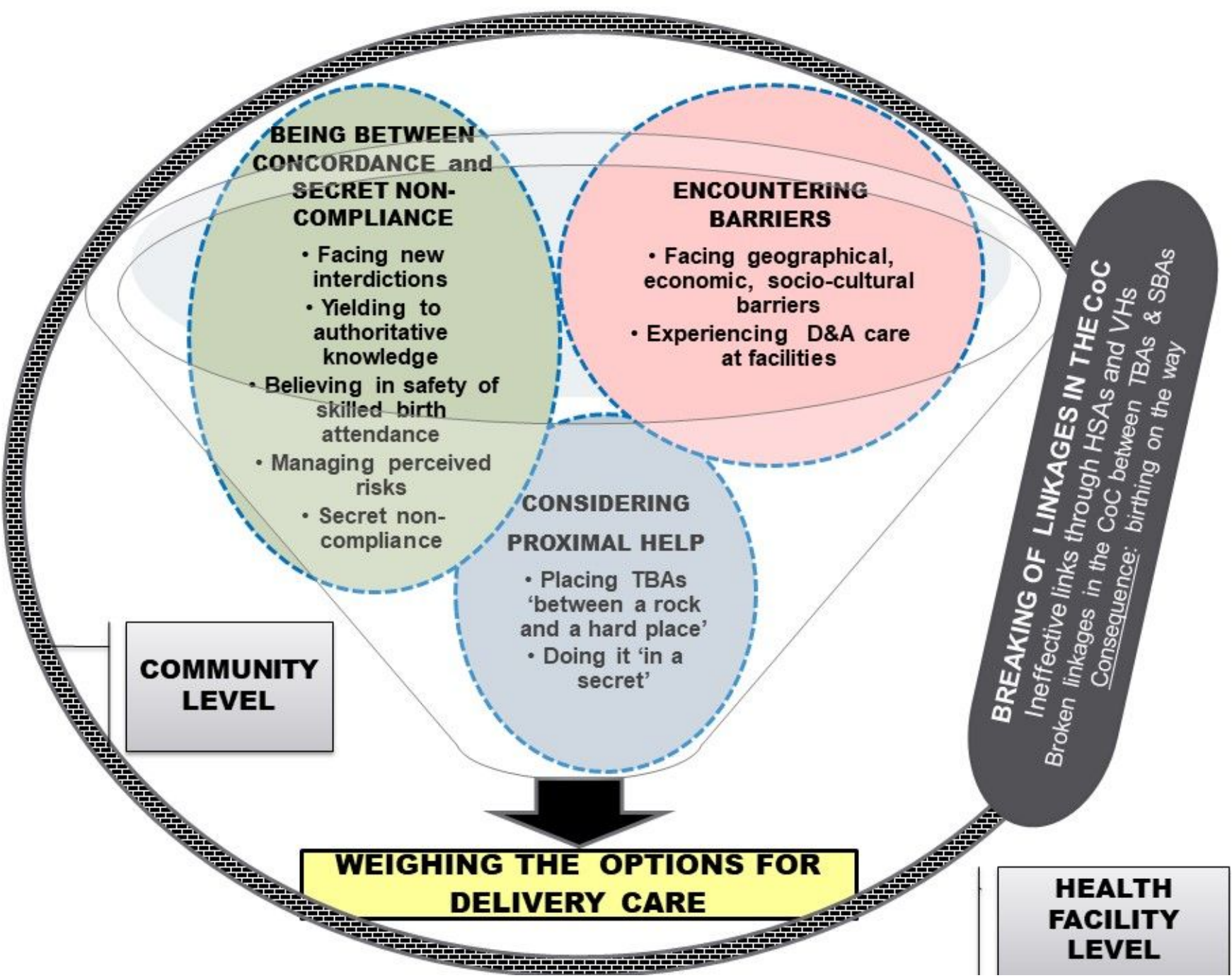

